\title{
A new bounding-surface plasticity model for cyclic behaviors of saturated clay
}

\author{
Cun $\mathrm{Hu}^{\mathrm{a}, \mathrm{b}}$, Haixiao Liu ${ }^{\mathrm{b}, *}$ \\ ${ }^{a}$ Institute of Mechanics, Chinese Academy of Sciences, Beijing 100190, China \\ ${ }^{\mathrm{b}}$ School of Civil Engineering, Tianjin University, Tianjin 300072, China
}

\section{A R T I C L E I N F O}

\section{Article history:}

Received 24 February 2012

Received in revised form 15 October 2014

Accepted 15 October 2014

Available online 23 October 2014

\section{Keywords:}

Bounding-surface plasticity model

Saturated clay

Cyclic loading

Cyclic behavior

Generalized homological center

\begin{abstract}
A B S T R A C T
A new combined isotropic-kinematic hardening rule is proposed based on the concept of the generalized homological center and the generalization of Masing's rule. The key point of the new hardening rule is that the unloading event can be treated as if it were virgin loading through taking the stress reversal point as the new generalized homological center of the bounding surface. Therefore, a new simple bounding-surface plasticity model with three important features for the cyclic behaviors of saturated clay is developed. Firstly, according to the movement of the generalized homological center, the model can harden not only isotropically but also kinematically to account for the anisotropy and memory the particular loading events. Secondly, the continuous cyclic loading is divided into the first loading, unloading and reloading processes and they are treated differently when calculating the hardening modulus to describe the soil responses accurately. The third feature is taking the generalized homological center as the mapping origin in the mapping rule to reflect the plastic flow in the unloading event. The behaviors of saturated clay for the monotonic and cyclic stress-controlled and strain-controlled triaxial tests are simulated by the model. The prediction results show an encouraging agreement with the experimental data.
\end{abstract}

(c) 2014 Elsevier B.V. All rights reserved.

\section{Introduction}

Offshore foundations, such as piles, suction anchors, bucket foundations and drag anchors, are often partially or completely embedded in seabed soils. The performance of such embedded foundations is strongly dependent upon the response of the surrounding soils, due to that under cyclic loads caused by waves and currents, significant changes can happen both in the stiffness and shear strength of soils [1-5]. The cyclic effects should be taken into account in the stability analysis of offshore foundations [6,7]. Hence, it is essential to develop more reliable and accurate soil models under long-term cyclic loading to effectively and precisely evaluate the response of embedded offshore foundations in a complicated ocean environment.

The observed typical response of a real soil undergoing cyclic loading is shown in Fig. 1 [8]. In Fig. 1, upon unloading both elastic and plastic deformations occur before the stress path is fully reversed, and cyclic loading can lead to a substantial accumulation in plastic deformation and pore pressure together with even a sudden loss in the shear strength and stiffness of the soil. Moreover, a natural deposited clay tends to be anisotropic because of the nature of its particles and environmental conditions, even the isotropic soils may present anisotropic.

\footnotetext{
* Corresponding author. Tel./fax: +86 2227401510 .

E-mail address: liuhx@tju.edu.cn (H. Liu).
} 
Over the last decades, there have been two remarkable types of plasticity models for cyclic behaviors of soils and other materials. One is the multi-surface model, which is based on the kinematic hardening plasticity theory [9,10], and the other is the bounding-surface plasticity theory, including the two-surface model which defines an outer surface termed as a bounding surface in addition to the inner surface or loading surface [11] and the single-surface model in which the elastic domain is reduced to a point within the consolidation or bounding surface [12-14]. Based on the two theories, many new models have been proposed and some successful results have been achieved. Mroz et al. [15] proposed a nesting yielding surface model, in which an infinite number of nesting yield surfaces within the consolidation surface translate in crowds, and they also harden isotropically during reverse loading. Li and Meissner [16] proposed a two-surface plasticity model based on a new kind of kinematic hardening rule, in which a new memory center is introduced to take into account the memory of the particular loading history, and meanwhile the memory center is considered as the mapping origin to predict the reversal plastic flow. Similarly, Khalili et al. [17] proposed a two-surface plasticity model for cyclic loading of granular soils, in which three surfaces are implied and the stress reversal point is taken as the homological center of the loading surface in order to reflect the loading history. However, because of their complicated hardening rules, which need to account for the evolution of more than two surfaces, it is difficult to be implemented in a numerical simulation or to solve a boundary value problem especially the ones referring long-term cyclic loading.

Among the above plasticity models, the bounding-surface plasticity model with vanishing elastic region has particularly attracted a great deal of interest due to its simplicity and ease of use. However, the conventional models [12-14,18,19] are usually based on assumptions that the bounding surface hardens isotropically along the hydrostatic pressure axis and the unloading response is elastic. So they are failed to predict the real cyclic responses of soils such as anisotropy and reverse plastic flow. By introducing the fabric tensor or a new rotational hardening rule, which consists of both the deviatoric and volumetric components, the single bounding-surface model can be applied to predict the material anisotropy [20,21]. However, a great number of additional parameters should be introduced into and this increases complexities of the model. Moreover, some of important features of soils subjected to cyclic loading still cannot be predicted satisfactorily by these single bounding-surface models.

The aim of the present study is to present a new simple combined isotropic-kinematic hardening rule and to develop a simple but accurate bounding-surface plasticity model for saturated clay subjected to cyclic loading. A new mapping rule is established by taking the generalized homological center as a new mapping center. The applicability and veracity of the bounding-surface plasticity model are demonstrated by comparing with the test results of saturated clay from the literature.

\section{The single bounding-surface model based on a new combined isotropic-kinematic hardening rule}

For a monotonic loading process, the isotropic hardening plasticity model can be successfully applied in solving boundary value problems. However, for cyclic loading processes, the classical bounding-surface models based on the isotropic hardening rule are not appropriate for modeling soil behaviors due to the following reasons [22]:

a. Soil exhibits the material anisotropy (analogous to the Bauschinger effect in metals).

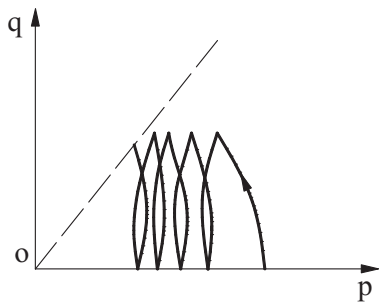

(a) Effective stress path

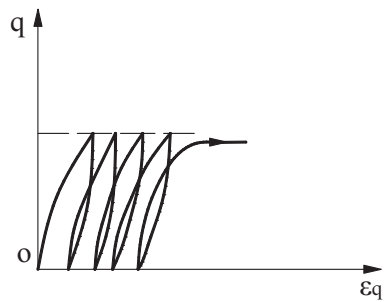

(b) Stress-strain relations

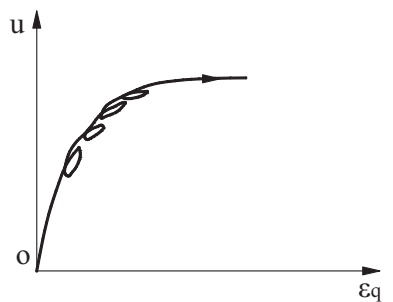

(c) Pore pressure-strain response

Fig. 1. Typical response observed in cyclic loading of clay. 
b. It is observed in soil experiments that upon unloading, both elastic and plastic deformations occur well before the stress path is fully reversed so that the stress-strain curve shows obvious hysteresis property. Whereas, the classical isotropic hardening bounding-surface model regards the unloading process as elastic one.

c. The particular loading events may change the soil structure and have a great influence on the subsequent soil properties, so the memory of particular loading events should be properly incorporated into the soil model.

\subsection{The new combined isotropic-kinematic hardening rule}

The present model is based on assumptions that the elastic domain enclosed by the bounding surface is reduced to a point, plastic flow occurs immediately for any stress increment within the bounding surface, and the degree of consolidation of a soil is represented by the bounding surface, which is uniquely defined by the irreversible volumetric strain $\varepsilon_{v}^{p}$ and represents the isotropic properties of the material during loading.

The conventional isotropic hardening rule assumes that the yield surface expands radially around a homological center, i.e., the center of the yield surface. Mroz et al. [15] assumed the stress reversal point as the homological center of the yield surface in the multi-surface plasticity model. While, Hashiguchi [23] and Lee and Oh [24] assumed that the homological center of the yielding surface could be translating and need not be its geometric center. In this paper, a new concept, termed as the generalized homological center of the bounding surface, is introduced. Its evolution rules are: for the virgin loading, the generalized homological center locates at the origin of the stress space, and for the nonvirgin loading, it moves to the stress point where the loading path abruptly changes its direction. Any abrupt changes in the loading direction satisfy the following condition:

$$
\frac{\partial F}{\partial \bar{\sigma}_{i j}} d \sigma_{i j} \leqslant 0
$$

where, $\overline{\sigma_{i j}}$ is the image point corresponding to $\sigma_{i j}$ (the details can be seen in Section 2.3 ). Thus, the generalized homological center divides the continuous cyclic loading into first loading, unloading and reloading events. It is convenient to consider the generalized homological center as a discrete internal memory variable whose role is to store up material memory events associated with abrupt changes of the loading direction. As mentioned above, the isotropic hardening rule can predict reasonable response for monotonic loading. It is expected that if each loading event which is divided from the cyclic loading can be considered as a proper monotonic loading event, then the cyclic loading could be predicted by a corresponding isotropic hardening rule. As is known, the isotropic hardening rule is easier to deal with and contains fewer variables than other hardening rules. Actually, it is a generalization of Masing's rule [25] which assumes that taking the stress reversal point as the loading origin, the reversed branch of the stress-strain curve can be obtained by magnifying the uniaxial curve by a factor of two.

The cyclic loading processes can be divided into the first loading, unloading and reloading events. Each of the events can be depicted by the isotropic hardening of the bounding surface around different generalized homological centers. Furthermore, in the present work, we assume that the generalized homological center should be on the bounding surface, which implies that once the new generalized homological center is formed, the bounding surface should translate along the line that connects the new homological center and the stress reversal point in the stress space to ensure the homological center on it. As a result, the new proposed hardening rule actually plays two roles. One is the isotropic hardening role, which assumes that the bounding surface hardens isotropically around a proper invariable generalized homological center for each loading or unloading sequence without the stress reversal point. The other is the kinematic hardening role, which consists of two parts. First, the translation of the bounding surface at the stress reversal point as described above. Second, a discrete formation of the generalized homological center can be regarded as a discontinuous rule for kinematic hardening. Note that to ensure the continuity of plastic deformations, the size of the new translating bounding surface is necessarily identical to the old one.

The new hardening rule is schematically represented in Figs. 2 and 3. For example, consider a case of undrained cyclic loading on a normally consolidated soil, where a bounding surface $F_{0}$ is defined by the virgin isotropic loading process $O A$, as shown in Fig. 2(a). The bounding surface is taken to be the yield surface of Modified Cam-clay, which is a simple ellipse. For the first shear loading after the initial consolidation, the stress path changes its direction at Point $A$ abruptly to the interior of $F_{0}$, as shown in Fig. 3(a). According to the rules mentioned above, the homological center shifts to the new position $A$ from the initial position $O$, then the bounding surface should translate along $\bar{A} A$ first to ensure the homological center on the surface. Meanwhile, the new bounding surface $F_{1}$ is formed and coincides with $F_{0}$ instantaneously, then it expands radially around the homological center $A$ in the following loading to form $F_{1}^{*}$. When the stress path reaches to Point $B$ and changes its direction, Point $B$ forms the new homological center and the bounding surface $F_{1}^{*}$ translates along the line $\bar{B} B$ to form a new bounding surface $F_{2}$, as shown in Fig. 3(b), and the size is identical to that of $F_{1}^{*}$. Within the subsequent loading, the bounding surface $F_{2}$ expands radially around the homological center $B$, as shown in Fig. 3(c). Similarly, when the stress path goes to Point $C$, the corresponding homological center $C$ and the bounding surface $F_{3}$ are formed, as shown in Fig. 3(d). Fig. 3(e) shows the corresponding stress-strain relations, in which Points $A, B, C$ correspond to those in Fig. 3(a)(d). The hardening rule can be regarded as a generalization of Masing's rule.

It can be seen that the whole bounding surface expands or contracts isotropically and translates with the generalized homological center in the stress space. This is different from the bounding-surface models which assume that the loading 


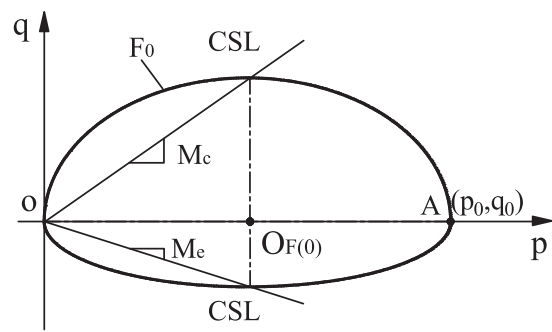

(a) During the isotropic consolidation

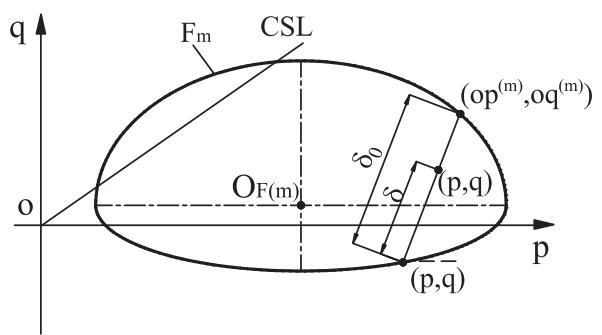

(b) During the $m$ th loading

Fig. 2. Schematic of the bounding surface in the $p-q$ stress space and geometrical interpretation of the radial mapping rule.

surface hardens kinematically and the bounding surface hardens isotropically or rotationally. However, the behavior of the bounding surface looks like a yield surface in the conventional theory of plasticity and stores up material memory like a multisurface model. Besides, the old bounding surface is erased once the new one forms. Therefore, only the evolution of the bounding surface in the stress space is involved in the new developed model. The corresponding hardening rule is fairly simple. It is an isotropic hardening rule with translating homological center intrinsically so it is easy to perform through numerical procedures. Also, it can be considered as a discontinuous kinematic hardening rule capable of modeling the soil anisotropy and remembering the particular loading history.

\subsection{The bounding surface}

In a critical state, the formulation of the bounding surface is usually assumed to be an elliptic form as:

$$
F_{m}=\left(\bar{p}-\alpha_{p}^{(m)}\right)^{2}+\left(\frac{\bar{q}-\alpha_{q}^{(m)}}{M}\right)^{2}-\left(a_{F}^{(m)}\left(\varepsilon_{v}^{p}, \varepsilon_{A}\right)\right)^{2}=0
$$

where, $\bar{p}$ and $\bar{q}$ represent the invariant components of the image stress which can be determined by the radial mapping rule (as shown in Fig. 2(b)), $\alpha_{p}^{(m)}$ and $\alpha_{q}^{(m)}$ are the coordinates of the center $O_{F(m)}$ of the bounding surface, $m$ is the ordinal number of particular loading events in which the stress path does not change direction, and $M$ is the slope of critical state line and can be determined by:

$$
M=\left\{\begin{array}{l}
M_{c}=\frac{6 \sin \varphi}{3-\sin \varphi} \text { for } q-\alpha_{q}^{(m)} \geqslant 0 \\
M_{e}=\frac{6 \sin \varphi}{3+\sin \varphi} \text { for } q-\alpha_{q}^{(m)}<0
\end{array}\right.
$$

in which $\varphi$ is the angle of internal friction at failure, and $M_{c}$ and $M_{e}$ are values of $M$ in triaxial compression and extension, respectively (as shown in Fig. 2).

In Eq. (2), $\varepsilon_{A}=\int\left|d \varepsilon_{v}^{p}\right|$ is the cyclic degradation parameter, and $a_{F}^{(m)}$ is the semidiameter of the ellipse in $p$ direction and can be interpreted by:

$$
a_{F}^{(m)}=\frac{a\left(\varepsilon_{v}^{p}\right)}{1+\varepsilon_{A}}
$$

Degradation of soft clay, which can be found in many marine deposits during cyclic loading at high stress level, has been well documented in numerous studies [26,27]. This effect is associated with the increase in pore pressure and remodeling of the soil structure during cyclic loading. It can be seen from Eq. (4) that $a_{F}^{(m)}$ depends on the value of $\varepsilon_{A}$. The degradation effect can be modeled by shrinking of the bounding surface with increasing value of $\varepsilon_{A}$. 


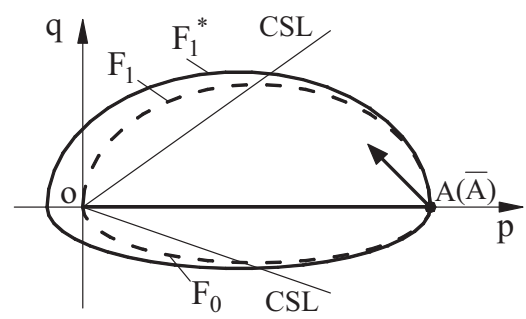

(a)

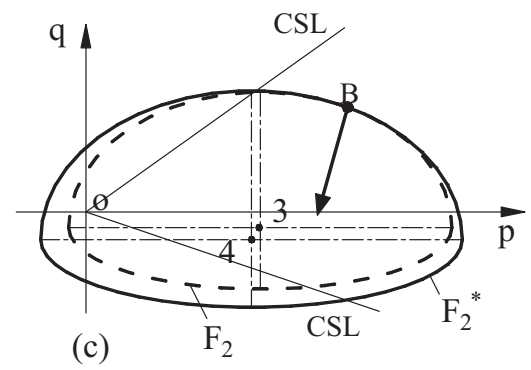

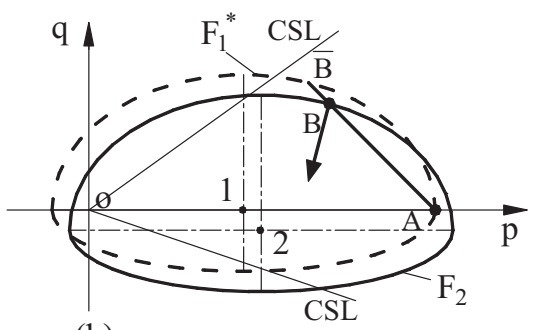

(b)

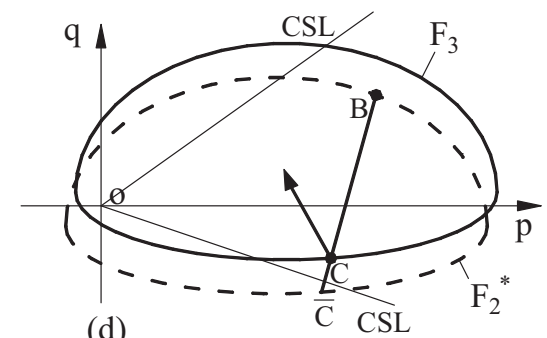

(d)

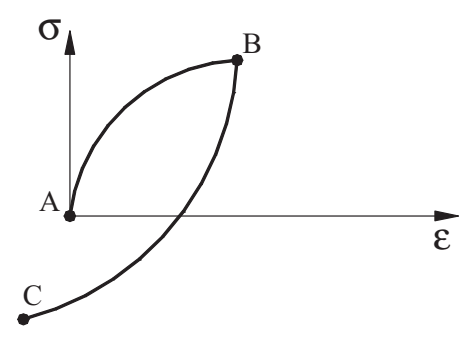

(e)

$$
1: \mathrm{OF}_{\mathrm{F}(\mathrm{m})} ; 2: \mathrm{OF}_{\mathrm{F}+1)} ; 3: \mathrm{O}_{\mathrm{F}(\mathrm{m}+1)}{ }^{(\mathrm{i})} ; \quad 4: \mathrm{O}_{\mathrm{F}(\mathrm{m}+1)}{ }^{(\mathrm{i}+1)}
$$

Fig. 3. Evolution of the bounding surface in the $p-q$ stress space.

\subsection{Mapping and flow rules}

In the present work, the form of the radial mapping rule proposed by Dafalias and Herrmann [12] is adopted. As shown in Fig. 2(b), any current stress state $\sigma_{i j}$ is associated with an image stress point $\overline{\sigma_{i j}}$, which is the intersection of the bounding surface with the straight line that passes the current stress state and the mapping origin. The key point of the mapping rule here is taking the generalized homological center (i.e., the stress reversal point) as the mapping origin. Correspondingly, the mapping origin can move in the stress space. The movement of the mapping origin plays two key roles: one is to make the model capable of appropriately describing the reverse plastic flow by obtaining a positive loading index during unloading events (details can be seen in Section 2.5); the other is to keep a large stiffness for the initial part of discrete loading or unloading events to avoid large deformation for small cycles (details can be seen in Section 2.6).

The associate flow rule is adopted in the present model. The direction of plastic loading $L_{i j}$ at the current stress state $\sigma_{i j}$, which is in line with the direction of plasticity flow, is defined as the gradient of $F$ at the image stress $\overline{\sigma_{i j}}$, i.e.,

$$
R_{i j}=L_{i j}=\frac{\partial F}{\partial \overline{\sigma_{i j}}}
$$

\subsection{The evolution of the bounding surface}

According to the new hardening rule, the bounding surface evolves in the stress space, and its size and location can be identified by the following methods.

The semidiameter $a_{F}^{(m)}$ can be formulated as: 


$$
a_{F}^{(m)}=\frac{a_{F}^{(0)} \exp \left\{\chi_{0}\left[\left(\varepsilon_{v}^{p}\right)_{m}-\left(\varepsilon_{v}^{p}\right)_{0}\right]\right\}}{1+\varepsilon_{A}}
$$

in which

$$
\chi_{0}=\frac{1+e_{0}}{\lambda-\kappa}
$$

where, $e_{0}$ denotes the void ratio after consolidation, $\left(\varepsilon_{v}^{p}\right)_{0}$ and $\left(\varepsilon_{v}^{p}\right)_{m}$ are plastic deformations corresponding to consolidation and current loading events respectively, $\lambda$ and $\kappa$ are model constants, and $a_{F}^{(0)}$ is the semidiameter of the initial bounding surface and mainly depends on the initial confining pressure.

When determining the coordinates of the center of the bounding surface, two cases should be noticed:

a. When the stress path changes the direction, $F_{m}$ translates along a particular path to form $F_{m+1}$ (as shown in Fig. 3(b)). The center of the active bounding surface $F_{m+1}$ is written as:

$$
\left\{\begin{array}{l}
\alpha_{p}^{(m+1)}=\alpha_{p}^{(m)}+(p-\bar{p}) \\
\alpha_{q}^{(m+1)}=\alpha_{q}^{(m)}+(q-\bar{q})
\end{array}\right.
$$

b. Upon the $(m+1)$ th loading event in which the stress path does not change direction, from the $i$ th to $(i+1)$ th loading substep, $F_{m+1}$ expands or contracts isotropically (as shown in Fig. 3(c)). The center of the active bounding surface $F_{m+1}$ is written as:

$$
\left\{\begin{array}{l}
\alpha_{p(m+1)}^{(i+1)}=o p^{(m+1)}+\left(\alpha_{p(m+1)}^{(i)}-o p^{(m+1)}\right) \frac{a_{F(n+1)}^{(i+1)}}{a_{F(m+1)}^{(i)}} \\
\alpha_{q(m+1)}^{(i+1)}=o q^{(m+1)}+\left(\alpha_{q(m+1)}^{(i)}-o q^{(m+1)}\right) \frac{a_{F(m+1)}^{(i+1)}}{a_{F(m+1)}^{(i)}}
\end{array}\right.
$$

In Eqs. (8a) and (8b), (pq) and ( $\overline{p q})$ are the current and image stress states respectively, $\left(\alpha_{p}^{(m+1)}, \alpha_{q}^{(m+1)}\right),\left(\alpha_{p(m+1)}^{(i)}, \alpha_{q(m+1)}^{(i)}\right)$ and $\left(\alpha_{p(m+1)}^{(i+1)}, \alpha_{q(m+1)}^{(i+1)}\right)$ denote the centers of bounding surfaces of the 0 th, $i$ th and $(i+1)$ th loading substeps in the $(m+1)$ th loading event respectively, $a_{F(m+1)}^{(i)}$ and $a_{F(m+1)}^{(i+1)}$ are the semidiameters of bounding surfaces of the $i$ th and $(i+1)$ th loading substeps in the $(m+1)$ th loading event respectively, and $\left(o p^{(m+1)}, o q^{(m+1)}\right)$ is the homological center of $F_{m+1}$, i.e., the coordinates of the stress reversal point.

\subsection{Elastoplastic incremental relations}

In bounding-surface plasticity, as in classical plasticity, the increment of strain is the sum of elastic and plastic strain increments and can be obtained by:

$$
\left\{\begin{array}{l}
d \varepsilon_{i j}=d \varepsilon_{i j}^{e}+d \varepsilon_{i j}^{p} \\
d \varepsilon_{i j}^{e}=\frac{1}{9 B} \delta_{i j} d \sigma_{k k}+\frac{1}{2 G} d \sigma_{i j} \\
d \varepsilon_{i j}^{p}=\langle L\rangle R_{i j}, \quad L=\frac{1}{K_{p}} L_{i j} d \sigma_{i j}=\frac{1}{\bar{K}_{p}} L_{i j} d \overline{\sigma_{i j}}
\end{array}\right.
$$

in which, $\delta_{i j}$ is the Kronecker's symbol, $K_{p}$ and $\overline{K_{p}}$ are the plasticity moduli of the current and image stress states respectively, $L$ is the loading index, and Macauly brackets \langle\rangle is defined as: $\langle L\rangle=L$ if $L>0$, and otherwise $\langle L\rangle=0$. It should be noticed that Macauly brackets in Eq. (9a) ensures that nonpositive values of loading index $L$ lead to $d \varepsilon_{i j}^{p}=0$.

The bulk modulus $B$ is usually assumed as:

$$
B=\frac{1+e_{0}}{\kappa} \sigma_{i i} / 3
$$

The shear modulus $G$ is related to the bulk modulus through a constant Poisson's ratio $v$ and can be formulated as:

$$
G=\frac{3(1-2 v)}{2(1+v)} B
$$

For the triaxial test condition, the effective stress state of a soil element can be described by two stresses and their corresponding strains:

$$
\left\{\begin{array}{l}
p=\frac{1}{3}\left(\sigma_{1}+2 \sigma_{3}\right), \quad q=\sigma_{1}-\sigma_{3} \\
\varepsilon_{v}=\varepsilon_{1}+2 \varepsilon_{3}, \quad \varepsilon_{q}=\frac{2}{3}\left(\varepsilon_{1}-\varepsilon_{3}\right)
\end{array}\right.
$$

The total stresses can be represented by $p^{t}=p+u$ and $q^{t}=q$, where $u$ is the pore pressure. 
From Eqs. (5), (9) and (10), it can be obtained:

$$
\left\{\begin{array}{l}
d \varepsilon_{v}^{e}=\frac{d p}{B}, \quad d \varepsilon_{q}^{e}=\frac{d q}{3 G} \\
d \varepsilon_{v}^{p}=\langle L\rangle n_{p}, \quad d \varepsilon_{q}^{p}=\langle L\rangle n_{q}
\end{array}\right.
$$

with

$$
\left\{n_{p}=\frac{\partial F}{\partial \bar{p}}, \quad n_{q}=\frac{\partial F}{\partial \bar{q}}\right.
$$

in which $n_{p}$ and $n_{q}$ denote the components of the gradient $L_{i j}$ of $F$ at the image stress point. It should be emphasized that taking the generalized homological center as the mapping origin ensures the positive value of the loading index $L$ for the unloading event. As shown in Fig. 4, during the $m+k$ loading event, the stress path $D E$ changes its direction and turns to the interior of the bounding surface at point $E$. Then, for the $m+k+1$ unloading event, the generalized homological center $E$ is taken as the mapping origin. Obviously, the positive value of $L$ can be obtained so that the plastic deformation in the reversal loading can be possibly simulated by the new model.

Because no volume change occurs during undrained deformation, the plastic compaction and elastic swelling must follow the relation:

$$
d \varepsilon_{v}=d \varepsilon_{v}^{e}+d \varepsilon_{v}^{p}=0
$$

From Eqs. (2), (11) and (12), the undrained effective stress path and the pore pressure can be represented by:

$$
\begin{aligned}
& \frac{d p}{d q}=\frac{-4 r^{2} B\left(\bar{q}-\alpha_{q}\right)\left(\bar{p}-\alpha_{p}\right)}{K_{p}+4 B\left(\bar{p}-\alpha_{p}\right)^{2}} \\
& d u=\frac{1}{3} d q+B\langle L\rangle n_{p}
\end{aligned}
$$

\subsection{Hardening plastic modulus}

A specific feature of bounding-surface plasticity is that the plastic modulus $K_{p}$ is not only dependent on the surface evolution but also an adjustable function of the distance between the current stress point and its image point on the bounding surface with the following requirements:

$$
\begin{array}{ll}
K_{p}=\infty & \text { if } \delta=\delta_{0} \\
K_{p}=\overline{K_{p}} & \text { if } \delta=0
\end{array}
$$

The consistency condition is adopted here, as follows:

$$
\frac{\partial F_{m}}{\partial \bar{p}} d \bar{p}+\frac{\partial F_{m}}{\partial \bar{q}} d \bar{q}+\frac{\partial F_{m}}{\partial \varepsilon_{v}^{p}} d \varepsilon_{v}^{p}=0
$$

Applying Eqs. (2), (6) and (11) to Eq. (16), leads to the expression of the hardening plasticity modulus on the bounding surface:

$$
\overline{K_{p}}=4 a_{F}^{(m)}\left(\bar{p}-\alpha_{p}+a_{F}^{(m)}\right)\left(\bar{p}-\alpha_{p}\right) \frac{\chi_{0}\left(1+\varepsilon_{A}\right) \pm 1}{\left(1+\varepsilon_{A}\right)^{2}}
$$

where, +1 is used if $d \varepsilon_{v}^{p}<0$, otherwise -1 is used.

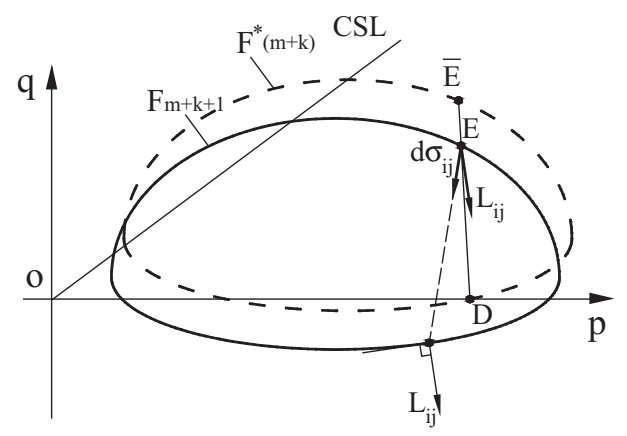

Fig. 4. Gradients of the plastic potential for the unloading event. 


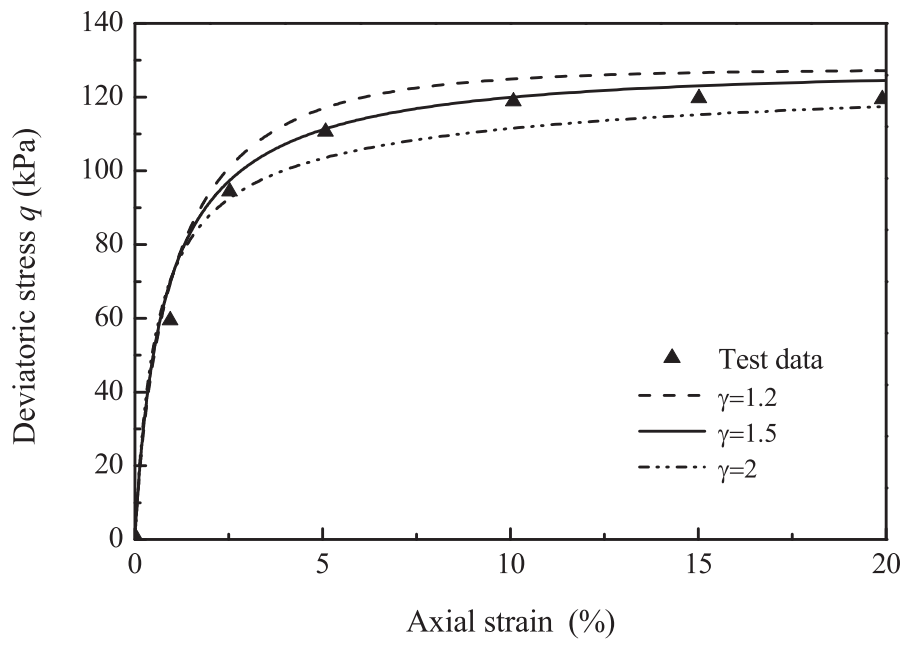

(a)

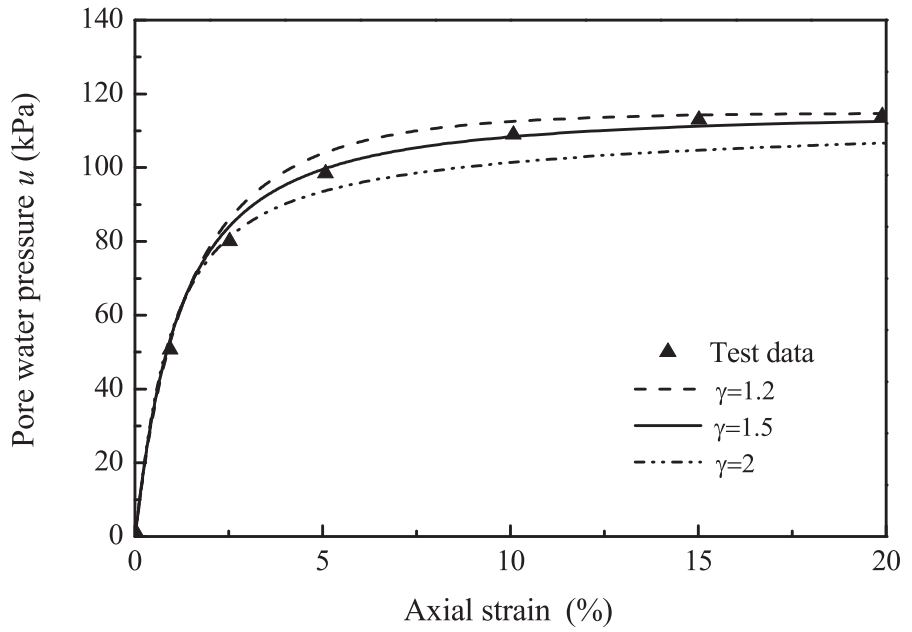

(b)

Fig. 5. Parameter calibration and sensitivity of monotonic shearing simulations to $\gamma$.

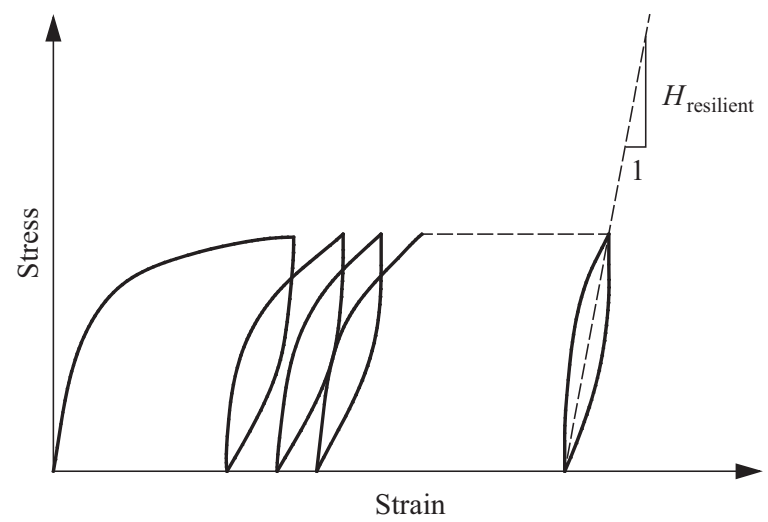

Fig. 6. Typical stress-strain curve of soil under cyclic loading. 


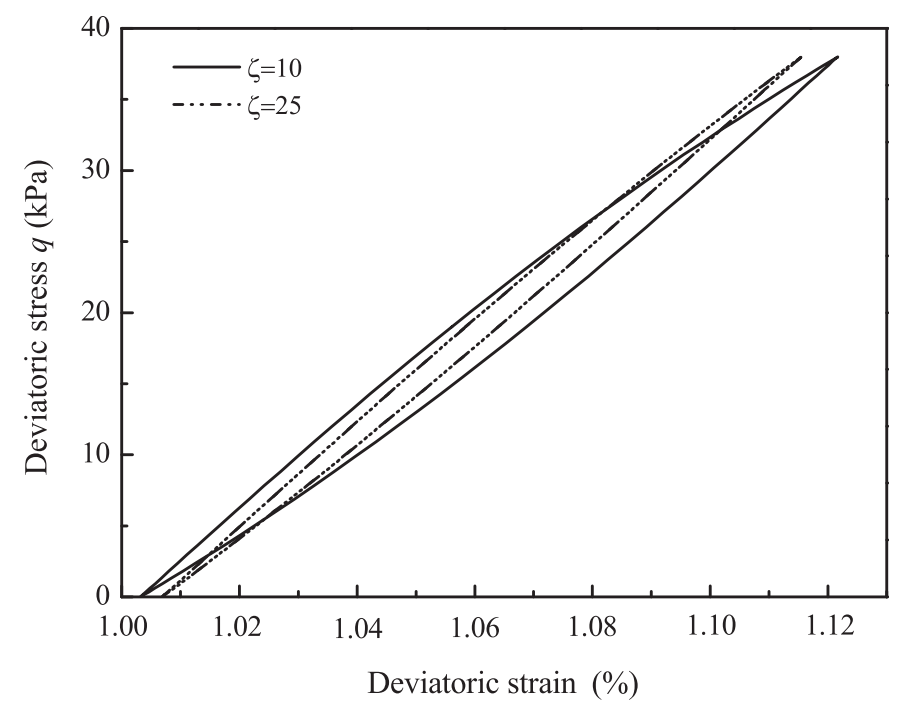

(a)

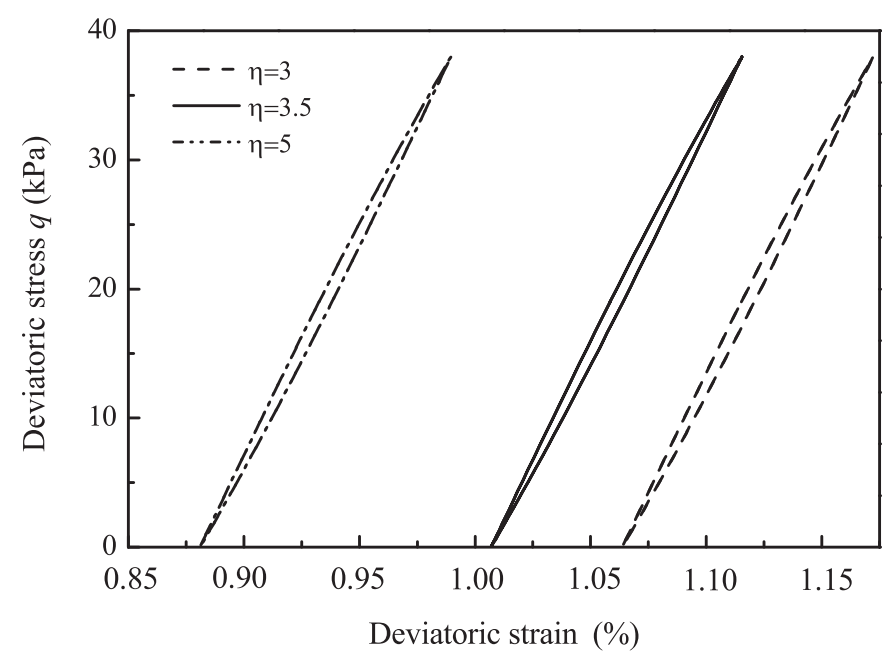

(b)

Fig. 7. Effects of parameters on the resilient hardening modulus $H_{\text {resilient }}$ : (a) $\varsigma_{r}$; (b) $\eta$.

The hardening plasticity modulus of the current stress state can be obtained by employing the interpolation rule:

$$
K_{p}=\overline{K_{p}}+H\left(\bar{p}, \bar{q}, \varepsilon_{v}^{p}\right)\left(\frac{\delta}{\delta_{0}-\delta}\right)^{\gamma}
$$

where, $H\left(\bar{p}, \bar{q}, \varepsilon_{v}^{p}\right)$ is the shape hardening function, $\delta_{0}$ and $\delta$ are the distances from the image point $(\bar{p}, \bar{q})$ to the mapping origin $(o p, o q)$ and the current stress point $(p q)$, respectively (as shown in Fig. 2(b)). $\gamma$ is a positive model constant which typically lies in the range of 1.0-2.0. If $\gamma=1$, Eq. (18) coincides with the interpolation rule adopted by Dafalias and Herrman [12].

One issue might draw our attention after giving the hardening rule. Even for a very small loading-unloading cycle, the bounding surface also translates suddenly in the stress space. Will this cause a significant change in response? After giving the mapping rule and the hardening modulus, the question can be clarified. From Eq. (18), it is known that the plastic hardening modulus at the current stress state $K_{p}$ is related with the distance function. For a small loading or unloading event, the loading or the unloading point is taken as the mapping center, which implies that $\delta$ is quite near to $\delta_{0}$ and leads the value of the distance function to be very large. As a result, the discrete translation of the bounding surface can not cause large deformation for small loading-unloading cycles.

By introducing discrete generalized homological centers, the continuous cyclic loading process is divided into three types of loading events, namely the first loading, unloading and reloading processes. In a conventional elastoplastic model, unloading and reloading processes are considered as one in terms of calculating the hardening modulus. However, in the 


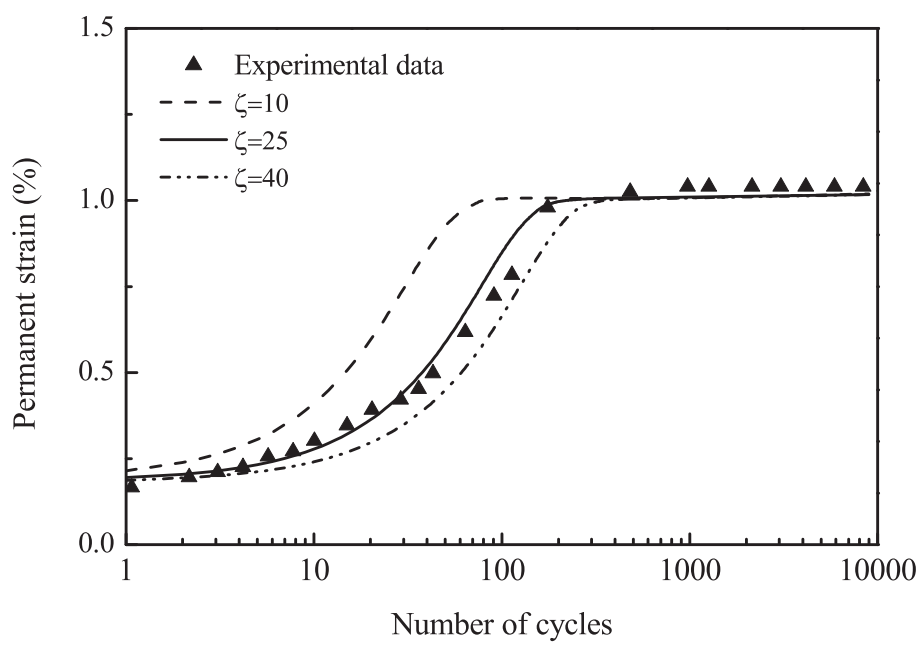

(a)

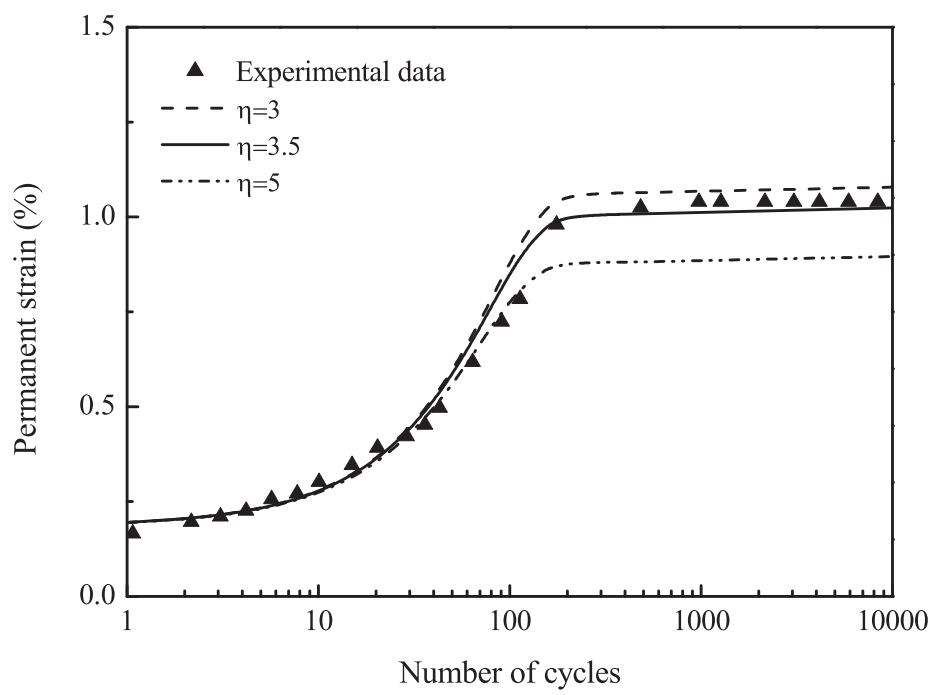

(b)

Fig. 8. Effects of parameters on the accumulation of permanent strain: (a) $\varsigma_{r}$; (b) $\eta$

present model, in order to predict the accumulation of permanent strain and pore pressure, the hardening modulus of the three loading events are treated differently by using different shape hardening functions, as follows:

$$
H\left(\bar{p}, \bar{q}, \varepsilon_{v}^{p}\right)= \begin{cases}\left|K_{m}-\overline{K_{p}}\right| & \text { for first loading } \\ \left|\varsigma_{u} K_{m}-\overline{K_{p}}\right| & \text { for unloading } \\ \left|\varsigma_{r} K_{m}-\overline{K_{p}}\right| & \text { for reloading }\end{cases}
$$

with

$$
K_{m}=8 \chi_{0}\left(a_{F}^{(m)}\right)^{3} \text { and } \frac{\varsigma_{u}}{\varsigma_{r}}=\left(\frac{M_{c}}{M_{e}}\right)^{2}\left(1+n_{p} / \eta\right)
$$

in which $\varsigma_{r}$ and $\eta$ are new model parameters. Eq. (20) enables no strain accumulation when the soil reaches the shakedown state. Details are presented in Section 4.3.

\section{Parameter calibration}

The proposed model requires eight material parameters as well as the initial stress state $\left(e_{0}, p_{0}\right)$. The parameters are related to the critical state soil mechanics $\left(\lambda, \kappa, M_{e}, M_{c}, G\right.$ or $\left.v\right)$ and the hardening modulus $\left(\gamma, \varsigma_{r}\right.$, $\left.\eta\right)$. The first five can be 
Table 1

Values of model parameters.

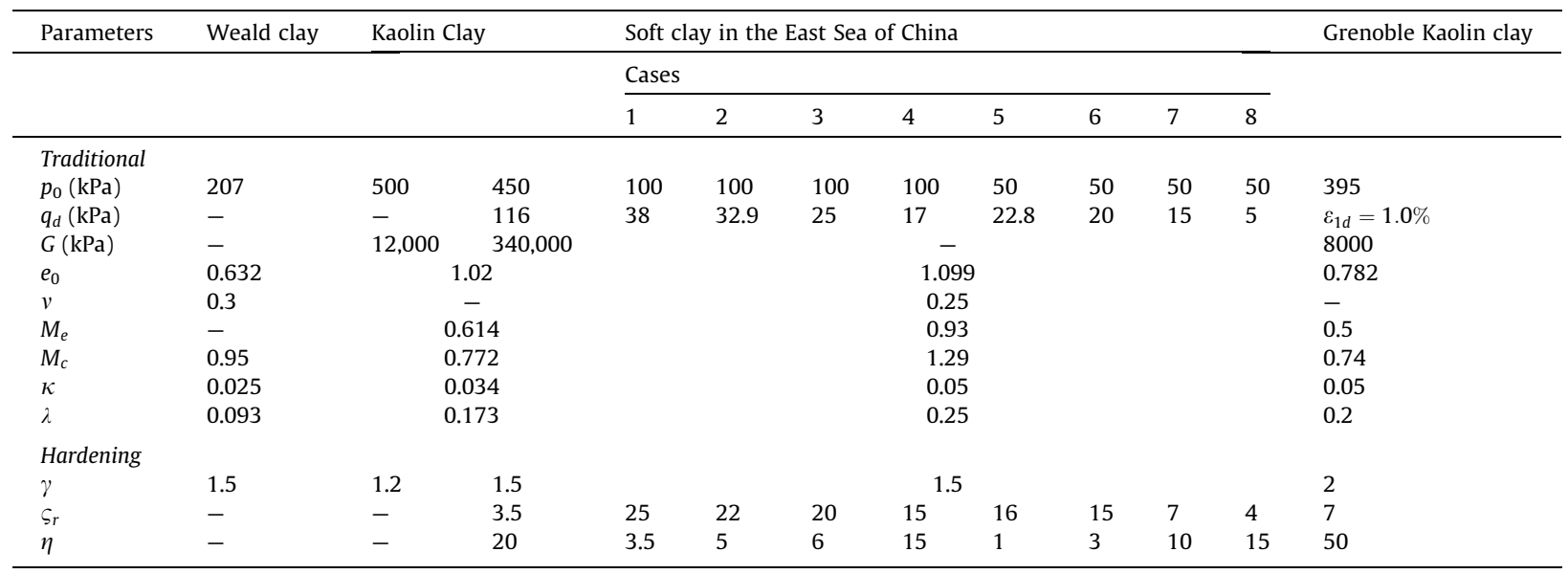

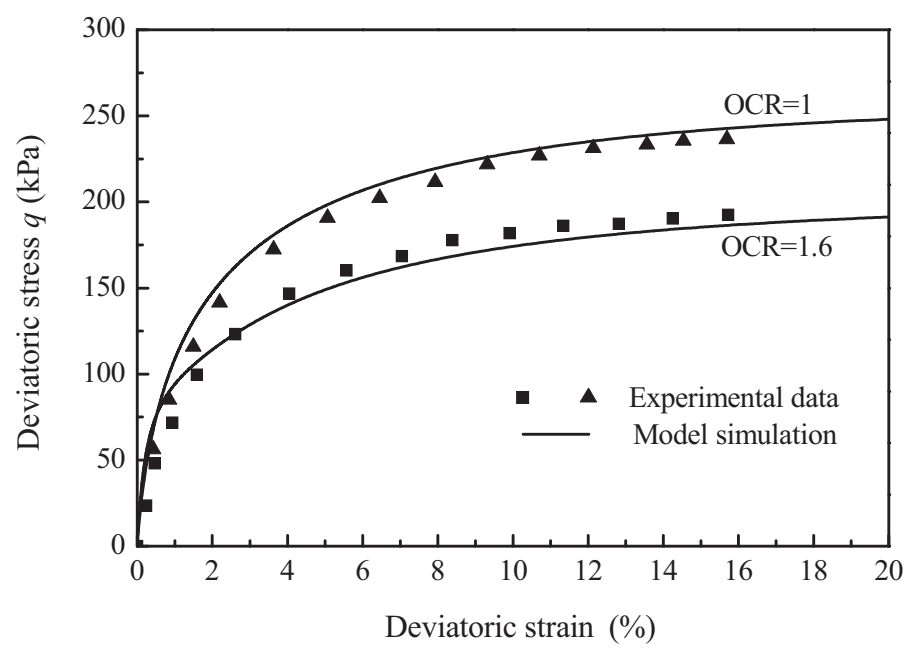

(a)

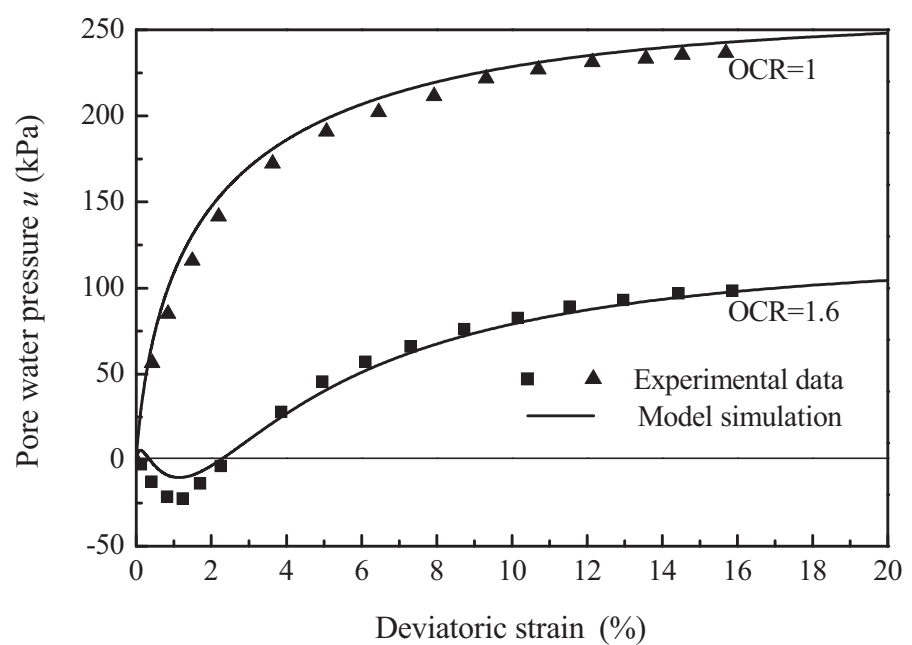

(b)

Fig. 9. Comparison of undrained monotonic responses of Kaolin clay between the predicted and measured data. 


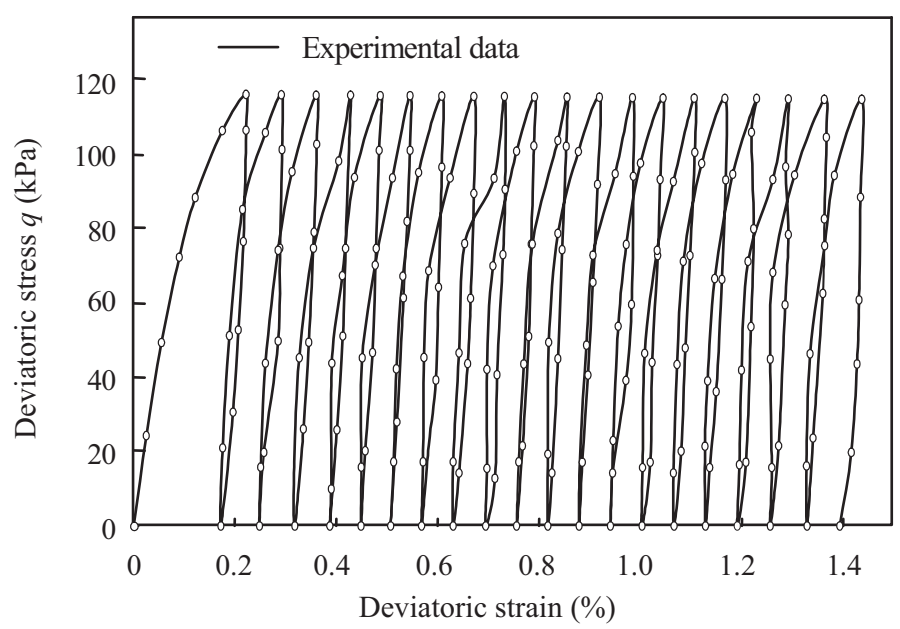

(a)

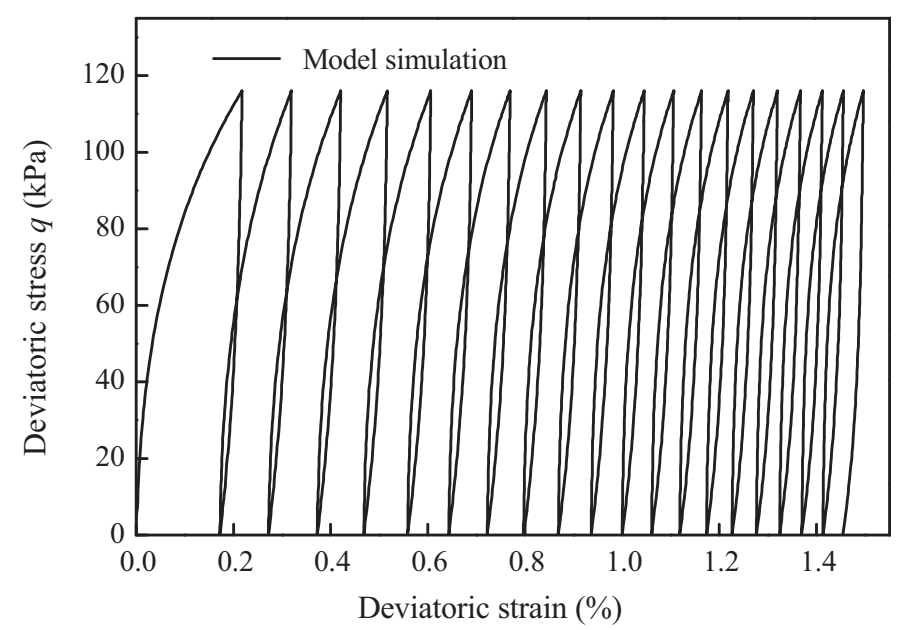

(b)

Fig. 10. Comparison of stress-strain relations between the predicted and measured data.

evaluated directly from in situ and laboratory tests and the remaining three must be obtained indirectly via trial-and-error simulations of laboratory tests. In the following sections, the roles of the eight parameters and the possible methods for determining their values are briefly discussed.

$\lambda$ and $\kappa$ are the slopes of the initial loading and unloading curves in the $e-\ln p$, and can be obtained from the isotropic consolidation tests. $M_{e}$ and $M_{c}$ are the slopes of the critical state lines as usual, whose values can be indirectly estimated from the angle of internal friction $\phi$. The calibration of their values requires monotonic element tests that approach the critical state. Elastic Poisson's ratio $v$ affects the value of the elastic bulk modulus $B$, and is typically in the range of $0.15-0.35$ for clay.

$\gamma$ can be deduced through simple trial and error simulations of undrained monotonic shearing, and the trial and error simulation just refers to $\gamma$ and the critical-state parameters. Test data from the classic series of tests, which were performed on normally consolidated remoulded Weald clay at Imperial College of London [28], were taken as the target responses. Several researchers have used the results for verifying the constitutive models [24,29]. In the investigation, the values of the traditional critical-state parameters are from Yu [29]. For Weald clay $\gamma=1.5$ was estimated in this manner. Fig. 5 shows the effects of $\gamma$ on the shearing response. It can be seen that the response is not dramatically affected by the changing values of $\gamma$ until the stress state approaches the bounding surface.

$\varsigma_{r}$ and $\eta$ are the material parameters related to reloading and unloading events, which control the steepness of the cyclic response in the $q-\varepsilon_{q}$ plane and are strongly influenced by the cyclic stress level and the history of consolidation. It is best to use the stress-strain relation of the first unloading-reloading cycle to obtain $\varsigma_{r}$ and $\eta$. The higher the value of $\varsigma_{r}$ is, the stiffer the stress-strain curve becomes. $\varsigma_{r}$ is expected to be a function of the resilient hardening modulus $H_{\text {resilient }}$ whose definition is given by Yu [19] and shown in Fig. 6. Figs. 7 and 8 present the roles and calibrations of $\varsigma_{r}$ and $\eta$ based on the tests on the soft clay from the East Coast of China [18], which were also used for assessing the model performance in Section 4.3. Taking the 


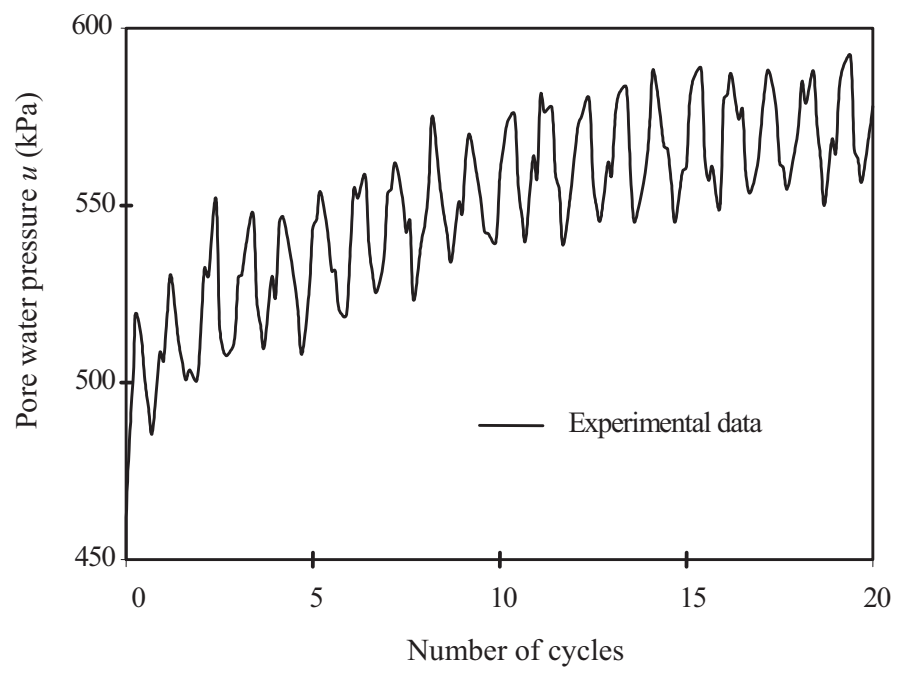

(a)

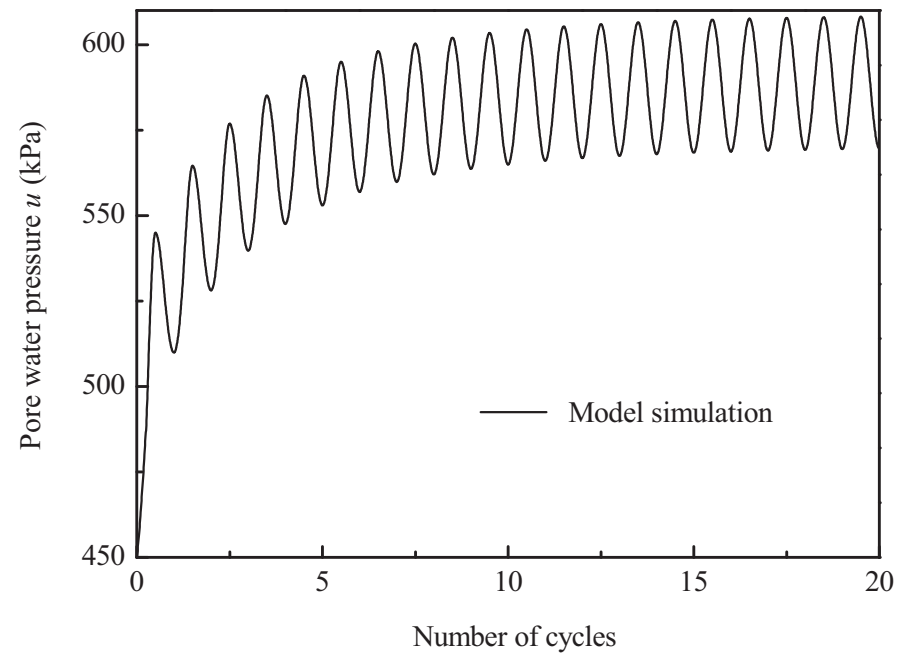

(b)

Fig. 11. Comparison of pore pressure between the predicted and measured data.

case ( $p_{0}=100 \mathrm{kPa}$ and $q_{d}=38 \mathrm{kPa}$ ) for example, Fig. 7 shows the effects of $\varsigma_{r}$ and $\eta$ on the resilient hardening modulus $H_{\text {resilient }}$. It can be seen that $H_{\text {resilient }}$ is determined by $\varsigma_{r}$ whereas $\eta$ has little effect on it. Fig. 8 shows the effects of $\varsigma_{r}$ and $\eta$ on the accumulation of permanent strain. Contrarily, it can be seen that the accumulation of plasticity strain is determined by $\eta$ whereas $\varsigma_{r}$ has little effect on it. For different soft clays, $H_{\text {resilient }}$ and the hysteresis property change with different cyclic stress levels and consolidation histories. The values of $\varsigma_{r}$ and $\eta$ can range from several to several tens.

\section{Verification of the model}

The performance of the proposed model to simulate the measured undrained response of saturated clay for monotonic and cyclic stress-controlled tests and strain-controlled triaxial tests was investigated by comparing the numerical simulation with the experimental results from the literature. The parameters used for the study are presented in Table 1.

\subsection{Monotonic tests on Kaolin clay}

Li and Messiner [16] conducted a series of undrained shearing tests on isotropically consolidated specimens with OCR $=1$ and $\mathrm{OCR}=1.6$. The initial conditions for the samples were $p_{0}=500 \mathrm{kPa}$ and $e_{0}=1.02$. The test results and the numerical simulation are shown in Fig. 9. For normally consolidated Kaolin clay, the parameter $\gamma$ was identical to that of the Weald clay. 


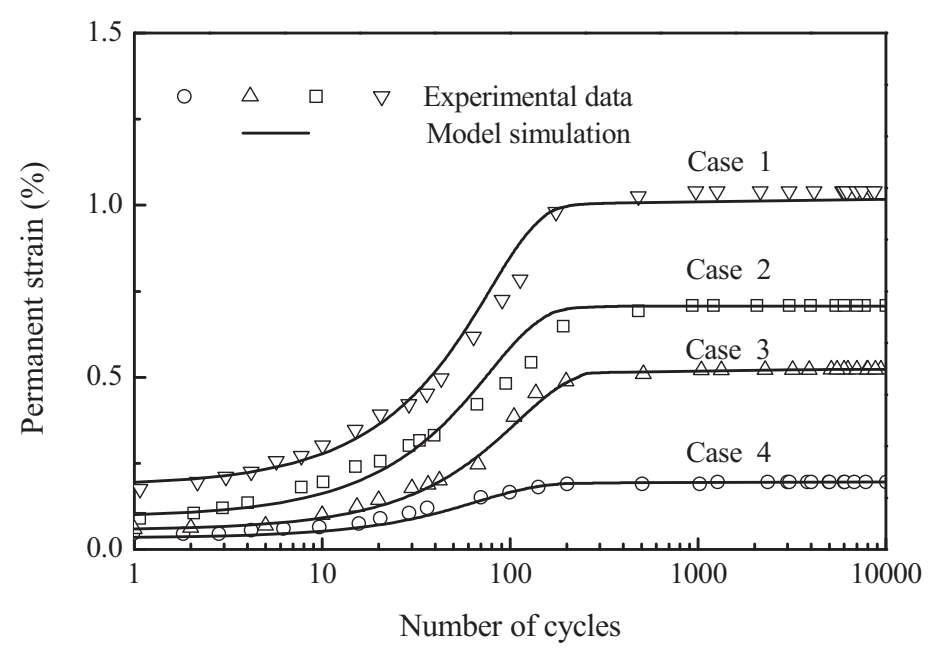

Fig. 12. Comparison of permanent strain between the predicted and measured data for $p_{0}=100 \mathrm{kPa}$.

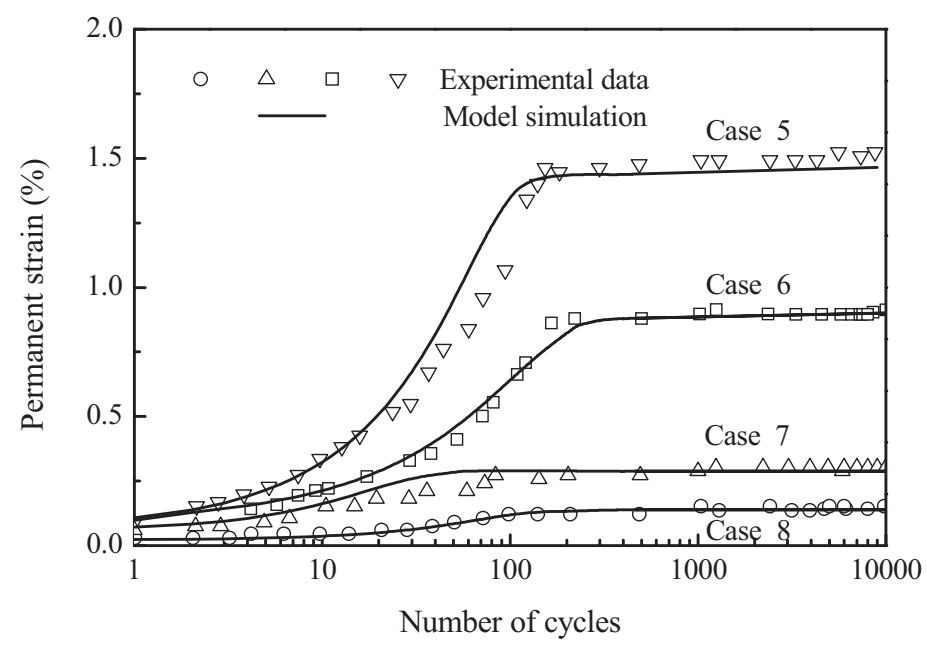

Fig. 13. Comparison of permanent strain between the predicted and measured data for $p_{0}=50 \mathrm{kPa}$.

While for the lightly overconsolidated one, the value of $\gamma$ was a little smaller. Fig. 9(a) presents the comparison of the deviatoric stress-strain relations between the tests and the model simulation. The comparison of the corresponding excess pore pressure versus the deviatoric strain is shown in Fig. 9(b). It can be seen that the predicted results generally agree well with the measured data, in spite of little overestimating the pore pressure in the early loading stage $(u \leqslant 0)$ for the lightly overconsolidated sample.

\subsection{Undrained cyclic triaxial test at short-term higher stress level}

In this section, some experimental results of commercially available Kaolin clay [16] continued to be used to assess the present model. In the experiments, the saturated clay specimen was isotropically consolidated to $450 \mathrm{kPa}$. The following cyclic test was stress-controlled, using the sinusoidal wave form with the wave frequency of $0.1 \mathrm{~Hz}$ and the magnitude of $116 \mathrm{kPa}$. The test program focused on the development of hysteretic loops, the accumulated plastic deformations and excess pore pressures under undrained conditions.

The predicted and measured stress-strain behaviors of clay subjected to a one-way undrained cyclic loading are presented in Fig. 10. It is seen that, the plastic strain of unloading part of a cycle, the accumulated plastic deformation and the evolvement of hysteretic loops are successfully reproduced by the present model. The comparison of the measured and predicted pore pressures is presented in Fig. 11. Although the predicted pore pressure is a little higher than the measured data, the general agreement is satisfactory. These figures demonstrate that behaviors of the undrained saturated clay subjected to cyclic loading at short-term high stress level can be predicted quantitatively by the present model. 


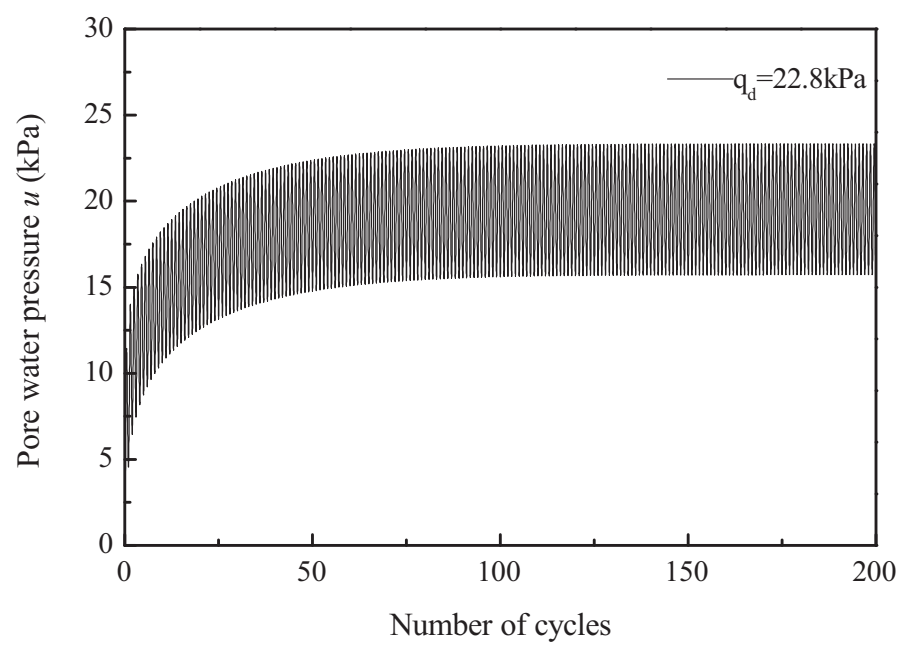

Fig. 14. Predicted transient pore pressure versus number of cycles for $p_{0}=50 \mathrm{kPa}$.

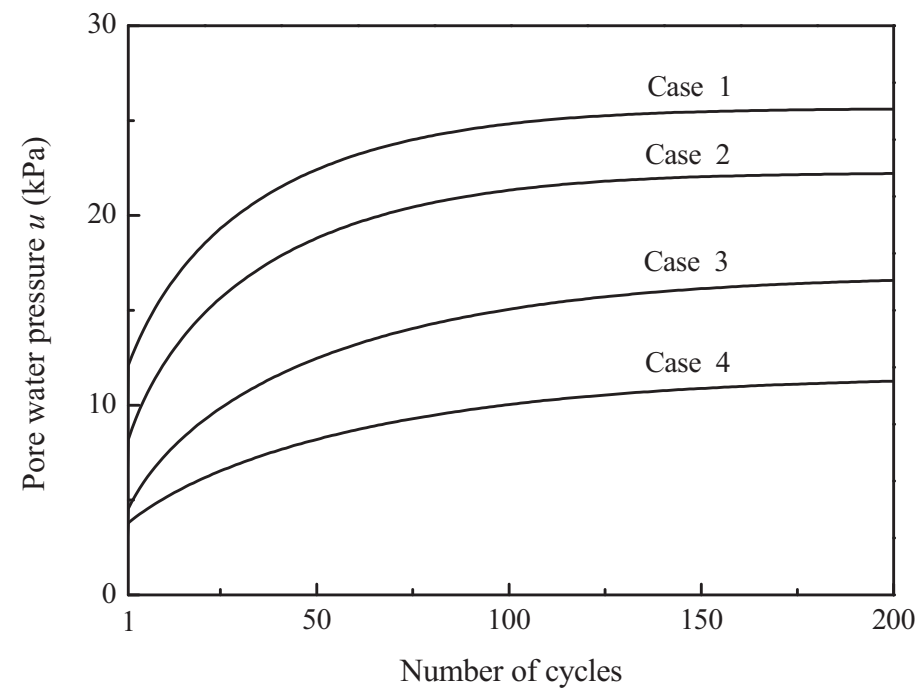

Fig. 15. Predicted residual pore pressure versus number of cycles for $p_{0}=100 \mathrm{kPa}$.

\subsection{Undrained cyclic triaxial tests at long-term lower stress level}

The response of soft clay in the East Coast of China subjected to cyclic loading at long-term lower stress level [18] was simulated by the present model, and compared with the experimental results. The soil samples used in the tests were isotropically consolidated under two different confining pressures, $p_{0}=50$ and $100 \mathrm{kPa}$. The following cyclic tests were stresscontrolled, using the sinusoidal wave form with the same wave frequency of $1 \mathrm{~Hz}$ but different magnitude $q_{d}$. The value of $q_{d}$ was in the range of $5-22.8 \mathrm{kPa}$ for $p_{0}=50 \mathrm{kPa}$ and in the range of $17-38 \mathrm{kPa}$ for $p_{0}=100 \mathrm{kPa}$.

The comparison of the accumulation of permanent strain between the measured and predicted data is presented in Figs. 12 and 13, which shows a better agreement. It can be seen that the soil response in the eight cases reaches the state of shakedown after a certain number of loading cycles. Figs. 14 and 15 show the predicted developments of transient and residual pore pressures, respectively. It can be seen that the pore pressure develops quickly in the earlier cycles, and the higher the stress level is, the more the accumulation of pore pressure becomes. After a certain number of cyclic loading, the development of pore pressure reaches a stable state. The evolutions of hysteretic loops and the corresponding effective stress path in the case $\left(p_{0}=50 \mathrm{kPa}, q_{d}=15 \mathrm{kPa}\right)$ during cyclic loading are presented in Figs. 16 and 17 , respectively. We can see from Fig. 17 that during the cyclic loading process, the proposed hardening rule (Section 2.2) enables the bounding surface to move towards the stress path. Finally, the minor axis of the bounding surface coincides with the stress path. As for the associated flow rule, there is no more plastic volumetric strain along the axis and the shakedown state is reached. Typical 


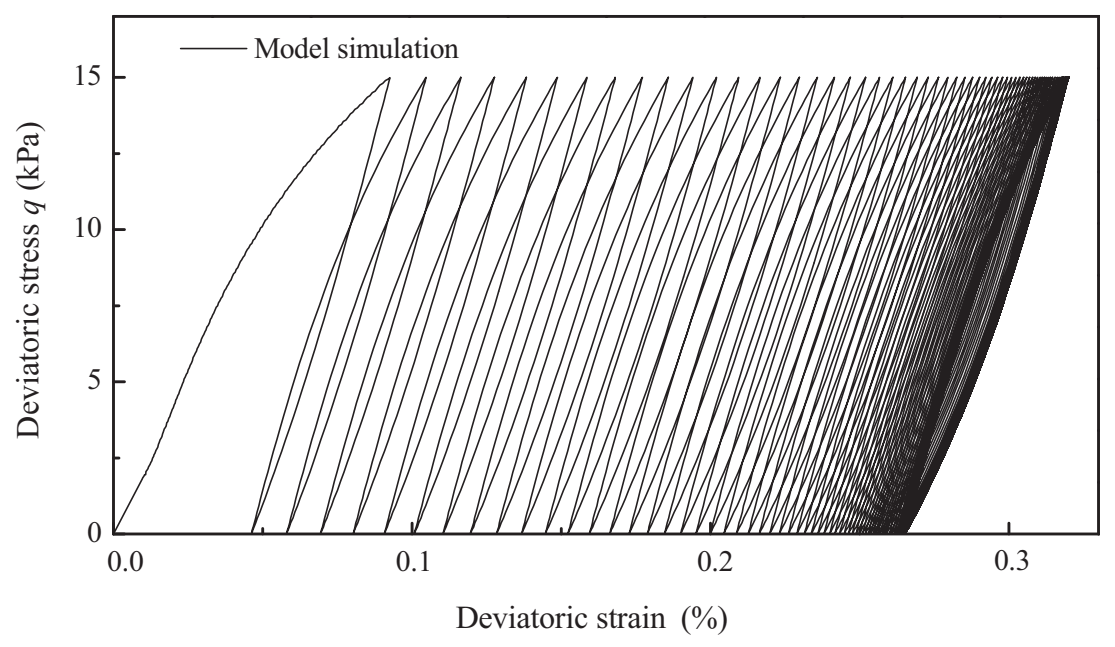

Fig. 16. Stress-strain relations for Case 7 from the model simulation.

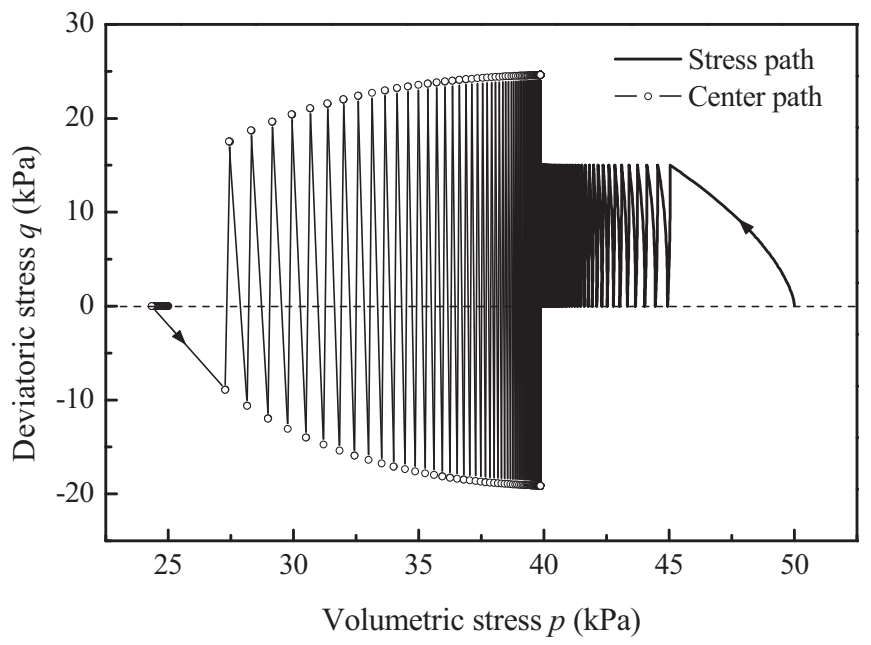

Fig. 17. Variations of stress path and bounding-surface center path for Case 7 in $p-q$ space.

hysteretic loop when the clay stays in the shakedown state is presented in Fig. 18, we can see that the deformation induced by the unloading part of the cycle is equal to that induced by the loading part of the cycle, and that there is no more accumulation of plastic strains. In this case, the ultimate response of clay is purely elastic and the soil will not fail under such a cyclic loading.

\subsection{Undrained cyclic strain-controlled test on Kaolin clay}

The application to simulation of strain-controlled cyclic behaviors of saturated clay was demonstrated using the test data reported by Kuntsche [30]. The test with the axial strain amplitude $\varepsilon_{1 d}=1.0 \%$ was performed on the specimen, which was isotropically consolidated with $p_{0}=395 \mathrm{kPa}$ and $e_{0}=0.782$. The critical-state parameters adopted here are from Liang and Ma [21].

Figs. 19 and 20 show the comparisons of the effective stress path and stress-strain relations of strain-controlled cyclic triaxial test between experimental results and model predictions. We can see from Fig. 19 that the effective stress path moves towards and finally reaches the critical state line (CSL), and the effective mean stress and the maximum deviatoric stress decrease with the increasing number of cycles. It can also be observed from Fig. 20 that the soil stiffness (i.e., the secant shear modulus) degrades during cyclic test. Apparently, the behavior of the clay under strain-controlled cyclic loading can be reasonably captured by the present model. 


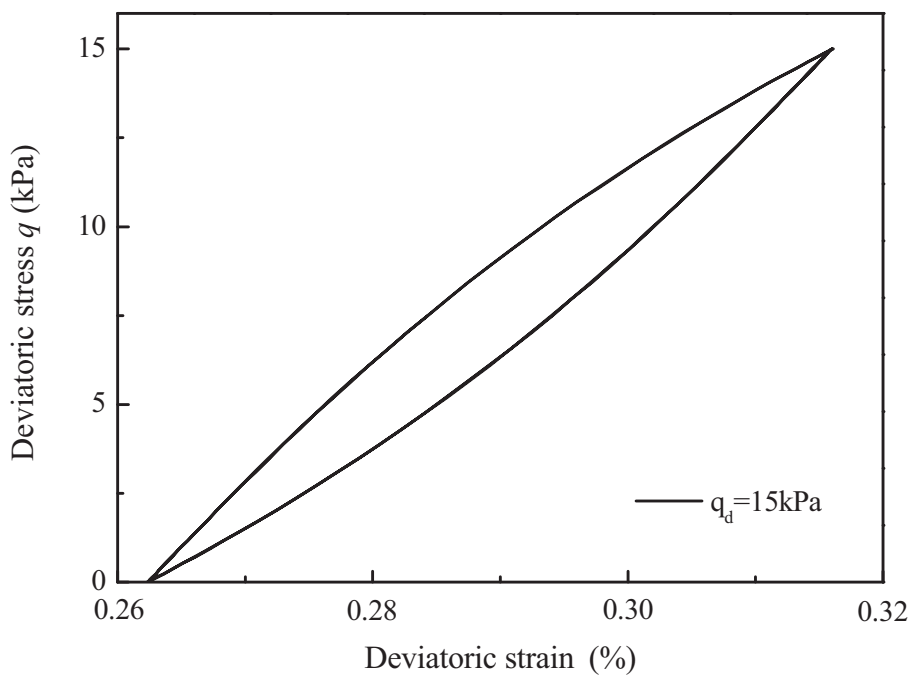

Fig. 18. Typical unloading-reloading hysteretic loop of clay in shakedown state.

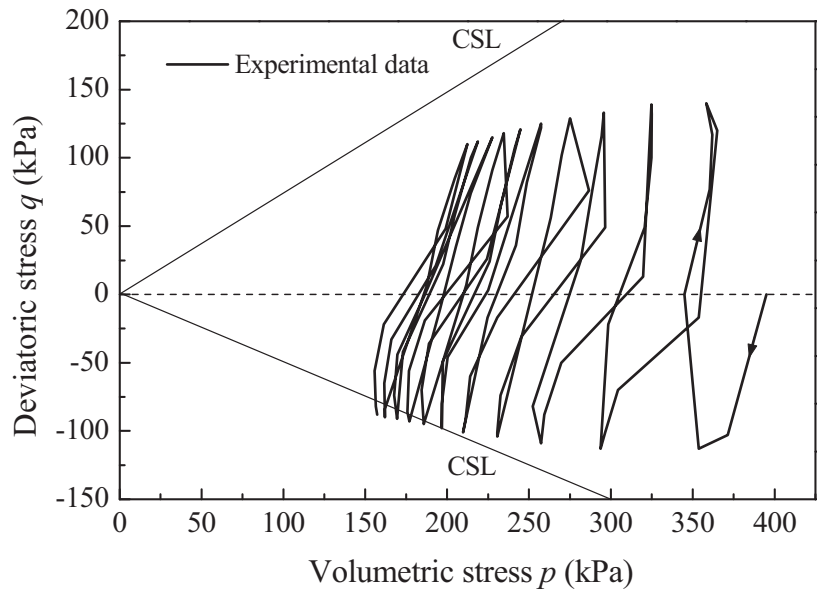

(a)

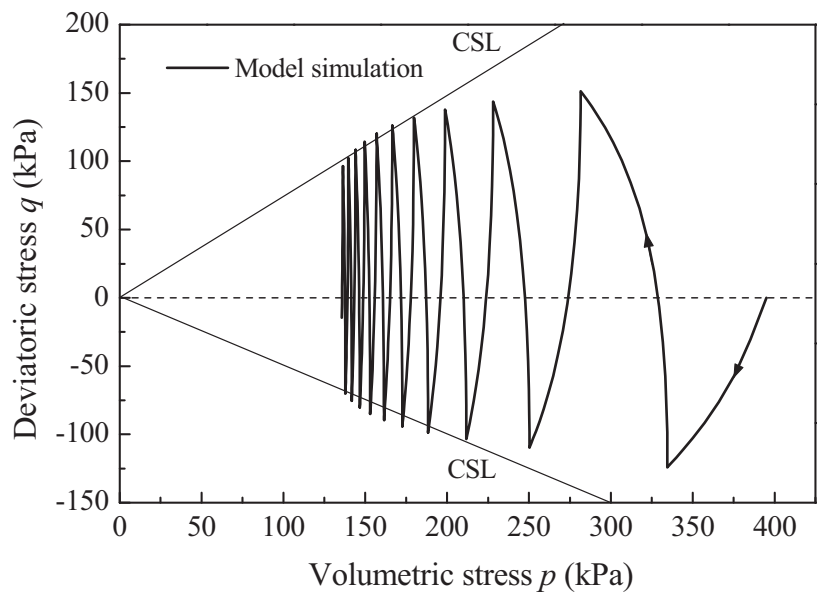

(b)

Fig. 19. Stress path of strain-controlled cyclic test on Kaolin Clay. 


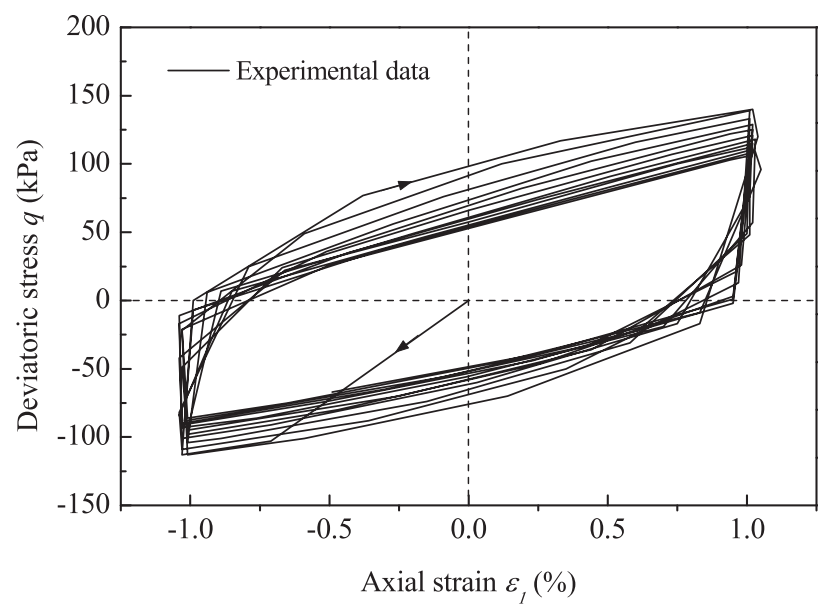

(a)

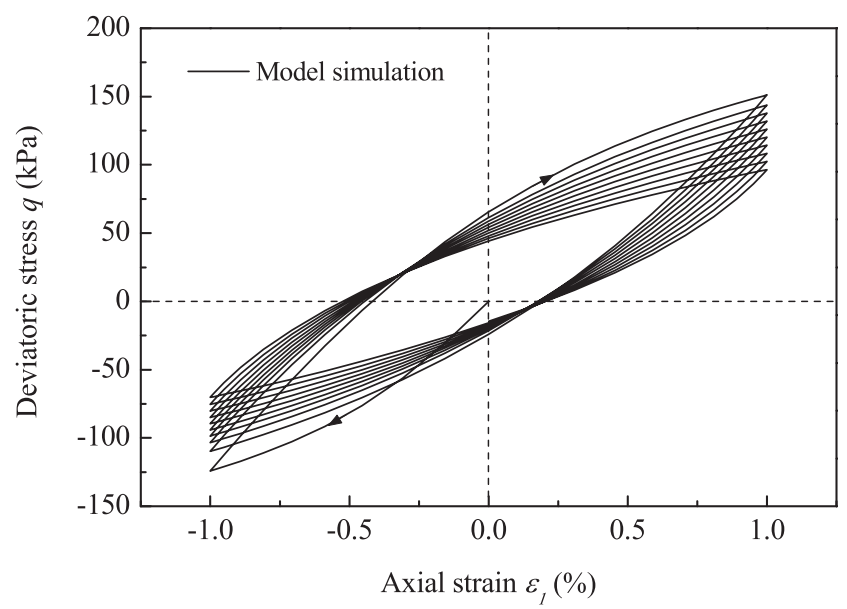

(b)

Fig. 20. Stress-strain relations of strain-controlled cyclic test on Kaolin Clay.

\section{Concluding remarks}

A bounding-surface plasticity model for simulating the behavior of undrained saturated clay under cyclic loading is presented. A new concept, termed as the generalized homological center, is introduced to discrete the cyclic loading into first loading, unloading and reloading events. As a generalization of Masing's rule, unloading and reloading events are treated as if they were monotonic loading events if taking the stress reversal point as the generalized homological center. Hence, each loading event is described by the isotropically hardening rule with a proper homological center. Beside that the new developed model is fairly simple to perform, there are three important features of the model. First, according to the movement of the generalized homological center, the developed model can harden not only isotropically but also kinematically in order to account for the evolution of clay anisotropy and to store up the particular loading events just like a multi-surface model. Second, the continuous cyclic loading is divided into the first loading, unloading and reloading processes, which are treated differently when calculating the hardening modulus in order to accurately describe the soil response for each loading event. The third feature is that the generalized homological center is taken as the mapping origin in order to depict a more realistic response during unloading and reloading.

To some extent, the present model contradicts the traditional single bounding-surface model where the bounding surface hardens isotropically or rotationally. However, the bounding surface in the new developed model can move in the stress space like a classic yield surface. It is a sort of link between the bounding-surface model and the conventional plasticity model. The simplicity and veracity of the present model have been verified by the comparative analysis on clays subjected to monotonic loading, stress-controlled cyclic loading at different stress levels and strain-controlled cyclic loading. The new developed model is able to capture the essential features of behavior in saturated clay, including the reverse plastic flow, the evolution of hysteretic loops, the development of pore pressure, the accumulation plastic deformations, the shakedown 
behavior as well as the soil stiffness degradation. Since the triaxial tests were used for calibration and validation, additional work should be conducted to verify the model with more general loading conditions, and also with the boundary-value problems.

\section{Acknowledgements}

Financial support from the National Natural Science Foundation of China (Grant Nos. 51309213, 51179124 and 50979070) is gratefully acknowledged. The first author would also like to thank Professor T. Li in Beijing Jiaotong University of China for his generous help with this research.

\section{References}

[1] Andersen KH, Lauritzsen R. Bearing capacity for foundations with cyclic loads. J Geotech Eng 1988;114(5):540-55

[2] Prasad YVSN, Rao SN. Experimental studies on foundations of compliant structures-II. Under cyclic loading. Ocean Eng 1994;21(1):15-27.

[3] Byrne BW, Houlsby GT. Experimental investigations of response of suction caissons to transient vertical loading. J Geotech Geoenviron Eng 2002;128(11):926-39.

[4] Singh SP, Ramaswamy SV. Response of plate anchors to sustained-cyclic loading. Indian Geotech J 2002;32(2):161-72.

[5] Chen W, Randolph MF. Uplift capacity of suction caissons under sustained and cyclic loading in soft clay. J Geotech Geoenviron Eng 2007;133(11):1352-63.

[6] Sangrey DA, Henkel DJ, Esrig MI. The effective stress response of a saturated clay soil to repeated loading. Can Geotech J 1969;6(3):241-52.

[7] Lefebvre G, LeBoeuf D. Stability threshold for cyclic loading of saturated clay. Can Geotech J 1989;26(1):122-31.

[8] Wood DM. Soil behavior and critical state soil mechanics. Cambridge University Press; 1990.

[9] Iwan DW. On a class of models for the yielding behaviour of continuous and composite systems. J Appl Mech 1967;34:612-7.

[10] Mroz Z, Norris VA, Zienkiewicz OC. An anisotropic hardening model for soils and its application to cyclic loading. Int J Numer Anal Methods Geomech $1978 ; 2(3): 203-21$

[11] Dafalias YF, Popov EP. A model of non-linearly hardening materials for complex loading. Acta Mech 1975;21:173-92.

[12] Dafalias YF, Herrmann LR. Bounding surface formulation of soil plasticity. In: Pande GN, Zienkiewicz OC, editors. Soil mechanics-transient and cyclic loads. New York: John Wiley \& Sons Ltd; 1982. p. 253-82.

[13] Dafalias YF. Bounding surface plasticity. I: mathematical foundation and hypoplasticity. J Eng Mech 1986;112(9):966-87.

[14] Dafalias YF, Herrmann LR. Bounding surface plasticity. II: application to isotropic cohesive soils. J Eng Mech 1986;112(12):1263-91.

[15] Mroz Z, Norris VA, Zienkiewicz OC. An anisotropic critical state model for soils subject to cyclic loading. Geotechnique 1981;31(4):451-69.

[16] Li T, Meissner H. Two-surface plasticity model for cyclic undrained behavior of clays. J Geotech Geoenviron Eng 2002;128(7):613-26.

[17] Khalili N, Habte MA, Valliappan S. A bounding surface plasticity model for cyclic loading of granular soils. Int J Numer Anal Methods Eng 2005;63:1939-60.

[18] Zhong HH, Huang MS, Wu SM, Zhang YJ. On the deformation of soft clay subjected to cyclic loading. Chin J Geotech Eng 2002;24(2):629-32.

[19] Yu HS, Khong C, Wang J. A unified plasticity model for cyclic behavior of clay and sand. Mech Res Commun 2007;34:97-114.

[20] Liang RY, Ma F. Anisotropic plasticity model for undrained cyclic behavior of clays. I: theory. J Geotech Eng 1992;118(2):229-45.

[21] Liang RY, Ma F. Anisotropic plasticity model for undrained cyclic behavior of clays. II: verification. J Geotech Eng 1992;118(2):246-65.

[22] Mroz Z, Norris VA. Elastoplastic and viscoplastic constitutive models for soils with application to cyclic loading. In: Pande GN, Zienkiewicz OC, editors. Soil mechanics-transient and cyclic loads. New York: John Wiley \& Sons Ltd; 1982. p. 173-217.

[23] Hashiguchi H. Subloading surface model in unconventional plasticity. J Solids Struct 1989;25(8):917-45.

[24] Lee SR, Oh S. An anisotropic hardening constitutive model based on generalized isotropic hardening rule for modeling clay behavior. Int J Numer Anal Methods Geomech 1995;19:683-703.

[25] Masing G. Eigenspannungen and Verfestigung beim Messing. In: Proceedings of the 2nd international congress of applied mechanics, Zurich; 1926. p. $332-5$.

[26] Idriss IM, Dobry R, Dolye EH, Singh RD. Nonlinear behavior of soft clays during cyclic loading conditions. J Geotech Eng Div 1978;104(12):1427-47.

[27] Matasovic N, Vucetic M. A pore pressure model for cyclic straining of clay. Soils Found 1992;32(3):156-73.

[28] Bishop AW, Henkel DJ. The measurement of soil properties in the triaxial test. London: Edward Arnold Publishers Ltd; 1957.

[29] Yu HS. CASM: a unified state parameter model for clay and sand. Int J Numer Anal Methods Geomech 1998;22:621-53.

[30] Kuntsche K. Tests on clay. In: Gudehus G, Darve F, Vardoulakis I, editors. Constitutive relations for soils, Rotterdam, The Netherlands; 1982 . p. 71-84. 